\title{
Negative Temperature Dependence of Recrystallized Grain Size: Formulation and Experimental Confirmation on Copper
}

\author{
Mohamed Elmasry, Fan Liu, Yao Jiang, Ze Ning Mao, Ying Liu * and Jing Tao Wang * \\ School of Material Science and Engineering, Nanjing University of Science and Technology, \\ Nanjing 210094, China; masrawy1975@yahoo.com (M.E.); liufan_njust@126.com (F.L.); \\ jiangyaonjust@126.com (Y.J.); maozening@163.com (Z.N.M.) \\ * Correspondence: liuying517@njust.edu.cn (Y.L.); jtwang@njust.edu.cn (J.T.W.); \\ Tel.: +86-25-8430-3983 (Y.L.); +86-25-8431-5493 (J.T.W.)
}

Academic Editor: Dinesh Agrawal

Received: 7 December 2016; Accepted: 10 March 2017; Published: 21 March 2017

\begin{abstract}
The catalyzing effect on nucleation of recrystallization from existing grains resulting from previous lower temperature deformation is analyzed, analogous to the size effect of foreign nucleus in heterogeneous nucleation. Analytical formulation of the effective nucleation site for recrystallization leads to a negative temperature dependence of recrystallized grain size of metals. Non-isochronal annealing-where annealing time is set just enough for the completion of recrystallization at different temperatures - is conducted on pure copper after severe plastic deformation. More homogeneous and smaller grains are obtained at higher annealing temperature. The good fit between analytical and experimental results unveils the intrinsic feature of this negative temperature dependence of recrystallized grain size.
\end{abstract}

Keywords: catalyzed nucleation; high angle grain boundary (HAGB); recrystallization; equal channel angular pressing (ECAP); negative temperature dependence

\section{Introduction}

The history of metalworking-including the procedures of deformation and heating-can be traced back to the early days of the Neolithic Age, when the first metalsmiths began working with native copper [1]. The birth of "recrystallization" was declared by a paper of 1887, where Sobey reported the emergence of new equiaxed grain when heating the deformed iron with elongated structure [2]. Establishing quantitative models based on the physics of recrystallization and using them to improve, optimize, and control microstructure has long been the crucial mission of the modern metal industry, and also the frontier of nanomaterials research [3].

In summarizing the "laws of recrystallization", it was stated by Burke and Turnbull $[4,5]$ that the final grain size obtained from recrystallization by annealing after deformation depends chiefly on the degree of deformation, and to a lesser degree on the annealing temperature-normally being smaller the greater the degree of deformation and the lower the annealing temperature. Experimental observations show that final grain size increases significantly with the increase of annealing temperature after pre-deformation in steel [6,7], $\mathrm{Cu}-\mathrm{Zn}$ alloys [8,9], magnesium alloy [10], molybdenum alloy [11], etc. However, on the other side, Eastwood et al. reported that recrystallized grain size is insensitive to annealing temperature and disclosed that different annealing temperatures yield a similar grain size after recrystallization for brass [12].

In addition to these contradictory experimental results, a basic gap in our knowledge for many years has been the lack of a quantitative model to account for the grain size after recrystallization [13]. 
One principal reason for the existence of this basic gap is the complexity of the recrystallization process - especially the complex nucleation behavior of pre-deformed materials. In order to reach a quantitative formulation of the recrystallized grain size, and to simultaneously avoid the complex problem related to the nucleation process, it will be helpful to quantitatively estimate the number of effective nucleation sites (which acts as a nucleus when dynamic conditions are satisfied during the nucleation process), which serves as an essential base for calculating the nucleation rate for recrystallization, and is always proportional to the final number of recrystallized grains after the completion of recrystallization.

The existing high angle grain boundaries (HAGB) in pre-deformed materials play an important role in promoting nucleation for recrystallization, through mechanisms such as strain-induced boundary migration (SIBM) [14]. Severe plastic deformation introduces a high density of non-equilibrium HAGBs, which serves as preferential nucleation site for recrystallization during annealing subsequent to the deformation, and significantly promotes the nucleation rate which leads to a much smaller recrystallized grain $[15,16]$. Analogous to the catalyzed nucleation by "foreign particles" during phase transformation, the catalyzing effect on nucleation of recrystallization from HAGB can be analyzed by following the work on foreign nuclei in heterogeneous nucleation $[17,18]$.

\section{Analytical Formulation of Catalyzed Nucleation by HAGB in Recrystallization}

Consider the catalyzing effectiveness on nucleation of recrystallization from an existing grain with a diameter of $d$ in the as-deformed microstructure with HAGBs, where the catalyzed embryo has a critical radius of $r^{*}$, which can be calculated from the classical nucleation theory [17]:

$$
r^{*}=\frac{2 \gamma}{\Delta G_{V}}
$$

where $\gamma$ is the interfacial energy and $\Delta G_{V}$ is the difference of Gibbs free energies per unit volume of the parent and new phases; in the present case of recrystallization, this Gibbs free energy difference equals to stored energy from pre-deformation, and is basically constant upon change of annealing temperature.

Fletcher [17] showed that the free energy of formation of a critical embryo with a radius of $r^{*}$ can be written as

$$
\Delta G^{*}=\frac{8 \pi \gamma^{3}}{3\left(\Delta G_{V}\right)^{2}} f(m, x)
$$

where $f(m, x)$ is known as the Fletcher shape factor for heterogeneous nucleation on a convex spherical catalyst particle, and can be given as

$$
f(m, x)=1+\left(\frac{1-m x}{g}\right)^{3}+x^{3}\left[2-3\left(\frac{x-m}{g}\right)+\left(\frac{x-m}{g}\right)^{3}\right]+3 m x^{2}\left(\frac{x-m}{g}-1\right),
$$

where $g=\left(1+x^{2}-2 m x\right)^{1 / 2} ; x=d /\left(2 r^{*}\right)$ is the dimensionless diameter of the spherical catalyst particle, normalized by the radius of critical embryo $r^{*}$, and $d$ is the actual dimeter of the catalyst particle; $m$-in the case of melt solidification-is the cosine of the contact angle of the new embryo on the catalyst surface, with $0 \leq m \leq 1$. In the present case of recrystallization, $m$ resembles the catalyzing efficiency of the pre-existing grain boundary on the formation of a new embryo for recrystallization, and could be considered constant in the case of high angle grain boundary misorientation. Thus, $f(m, x)$ is a function depending solely on $x$, the diameter of existing grains with HAGBs catalyzing the nucleation of recrystallization in subsequent annealing.

Generally, in dealing with the effect of foreign particle size on heterogeneous nucleation [19] and the nucleation issue of a pre-deformed material during recrystallization, probability has been used to relate nucleation activities with structure parameters in the parent phases (such as grain boundary misorientation, etc.) $[13,20]$. Hence, the probability $p$ for an existing grain in the pre-deformed matrix to act as an effective nucleation site for recrystallization is considered. It is reasonable to assume $p$ to 
be proportional to a thermal activation factor with $\Delta G^{*}$ as the energy barrier, and $f_{H A G B}$ the fraction of HAGBs which are evidenced to be preferential nucleation sites. Thus,

$$
p \approx C \exp \left(-\frac{\Delta G^{*}}{k_{B} T}\right) f_{H A G B}
$$

where $C$ is a coefficient, $T$ is the absolute temperature of annealing, and $k_{B}$ is the Boltzmann constant.

In considering the catalyzed nucleation by "foreign particles" during phase transformation, it is clear that the larger the diameter of the "foreign particle", the higher its efficiency in catalyzing the nucleation. Analogous to this tendency, suppose $p \approx 1$ at $x \geq x_{\mathrm{c}}$, which means grains in the pre-deformed matrix with HAGB and normalized dimensionless diameter $x$ larger than $x_{\mathrm{c}}$ will act as effective nucleation sites upon annealing at temperature $T$ with $100 \%$ possibility; and considering Equations (2) and (3),

$$
p \approx 1 \approx C \exp \left[-\frac{8 \pi \gamma^{3}}{3 \Delta G^{2} k_{B} T} f\left(m, x_{c}\right)\right] f_{H A G B}
$$

This leads to a relation between the annealing temperature $T$ and pre-existing grain size $x_{\mathrm{C}}$ :

$$
\frac{8 \pi \gamma^{3}}{3 \Delta G^{2}{ }_{V} k_{B} T} f\left(m, x_{c}\right)=T \ln \left(C f_{H A G B}\right)
$$

Fletcher [17] showed that shape factor $f\left(m, x_{\mathrm{c}}\right)$ increases monotonically upon decrease of $x_{\mathrm{c}}$, and Equation (5) gives a mathematically proportional relationship between $f\left(m, x_{\mathrm{c}}\right)$ and $T$; thus, the higher the $T$, the larger the $f\left(m, x_{\mathrm{c}}\right)$, and the smaller the $x_{\mathrm{c}}$, a drastic decrease of $x_{\mathrm{c}}$ upon $T$ is thus resulted.

Using typical parameters of $f_{H A G B}=0.67$ [21], $\Delta G_{V}=57 \mathrm{~J} / \mathrm{mol} \approx 8 \times 10^{6} \mathrm{~J} / \mathrm{m}^{3}$ [22] after severe plastic deformation, $\gamma=0.625 \mathrm{~J} / \mathrm{m}^{2}$ [2] for copper, and $C=1.51$, Equation (5) gives analytical results as shown in Figure 1. All the curves describing the dependence of $x_{\mathrm{c}}$ upon $T$ at different catalyzing efficiency $m$ indicate that the higher the annealing temperature $T$, the smaller the critical grain size $x_{c}$, and thus more grains in the pre-deformed matrix will act as effective nucleation sites. This means that higher annealing temperatures lead to smaller recrystallized grain size or a negative temperature dependence of recrystallized grain size, which is not only against the "laws of recrystallization" summarized by Burke and Turnbull [4,5], but also contradictory to the experimental results for copper [23-27], as well as other metals and alloys [6-11].

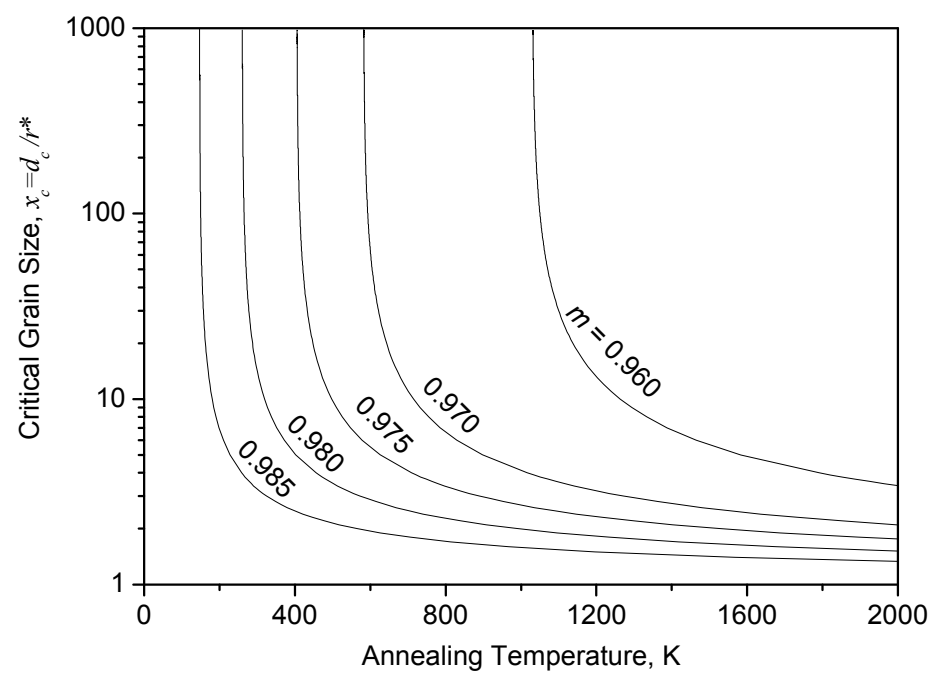

Figure 1. Dependence of critical grain size $x_{\mathrm{c}}$ upon annealing temperature $T$ at different levels of catalyzing efficiency $m$, which is large enough to sufficiently catalyze nucleation of recrystallization. 
In studying the recrystallization behavior of a two-phase brass, a negative temperature dependence of recrystallized grain size was observed by Naether et al. [9], where the reduction in the average grain size with increasing temperature was observed, accompanied by a concurrent increase of the volume fraction of $\beta$ phase in the sample. This case did not indicate the intrinsic negative temperature dependence of recrystallized grain size itself, but the increasing effect of $\beta$ phase stabilization from the concurrent increase of the volume fraction of $\beta$ phase in the sample upon increase of annealing temperature [9].

The key to unlocking this contradiction between the analytical formulation given in Equations (2)-(5) and the experimental data in the literature might be the annealing time. Isochronal annealing at different temperatures is usually used for the annealing and recrystallization to obtain temperature dependence of grain size in the literature [23-27]. When the annealing time is set to be enough for completion of recrystallization at a lower temperature, this isochronal annealing time is far more than that for recrystallization to complete at higher temperatures, and the grain size obtained in this case for high temperature annealing inevitably includes the effect of grain growth subsequent to the completion of recrystallization, and this leads to the resulting "pseudo-morph" of positive temperature dependence of grain size after "recrystallization".

To avoid the influence of this isochronal annealing issue and to obtain a true annealing temperature dependence of recrystallized grain size, kinetics of recrystallization processes could be characterized first, and the time just enough for the completion of recrystallization at each annealing temperature could thus be determined, which could then be used for non-isochronal annealing at different temperatures to obtain grain size immediately after the completion of recrystallization process. This non-isochronal annealing may remove the effect of grain growth after the completion of recrystallization, and obtain the intrinsic annealing temperature dependence of recrystallized grain size.

\section{Experimental Confirmation}

To confirm the negative temperature dependence of recrystallized grain size unveiled by the above analytical formulation, cold rolled (CR) high purity copper $(99.97 \mathrm{wt} \%)$ after equal channel angular pressing (ECAP) was used.

Hot rolled high purity copper with initial heat treatment at $873 \mathrm{~K}\left(600{ }^{\circ} \mathrm{C}\right)$ for $1 \mathrm{~h}$ to achieve a homogenous microstructure with an average grain size of $\sim 100 \mu \mathrm{m}$ was used in this study. Billets with size of $32 \times 32 \times 160 \mathrm{~mm}^{3}$ were processed by ECAP at room temperature with a die angle of $90^{\circ}$ for eight passes using route $\mathrm{Bc}$ [28]. The sample was then cold rolled at room temperature to a thickness reduction of $\sim 75 \%$. After pre-deformation through ECAP $+\mathrm{CR}$, annealing was conducted at temperatures ranging from $373 \mathrm{~K}\left(100^{\circ} \mathrm{C}\right)$ to $573 \mathrm{~K}\left(300^{\circ} \mathrm{C}\right)$ for times ranging from 3 to $48,000 \mathrm{~s}$. Vickers microhardness was measured at room temperature with a load of $100 \mathrm{~g}$ for $10 \mathrm{~s}$. More than 20 random indentations were made to obtain a representative bulk hardness value. Electron back-scattering diffraction (EBSD) technique was used to characterize microstructural evolution on the cross-sections of the ECAP + CR samples during annealing treatment, and grain boundaries with a misorientation angle $\geq 15^{\circ}$ were considered HAGBs. Figure 2 shows the EBSD microstructure of the sample after cold rolling (Figure 2a) and its grain size distribution (Figure $2 b$ ). The HAGB fraction of the materials was $\sim 68 \%$.

The recrystallization kinetics of the ECAP + CR samples upon annealing was characterized by the microhardness variations versus annealing time for different isothermal annealing temperatures, as shown in Figure 3, which indicates that when the annealing temperature increased from $413 \mathrm{~K}$ $\left(140{ }^{\circ} \mathrm{C}\right)$ to $573 \mathrm{~K}\left(300^{\circ} \mathrm{C}\right)$, the time for the completion of the recrystallization was reduced from $8 \mathrm{~h}$ to $35 \mathrm{~s}$. 

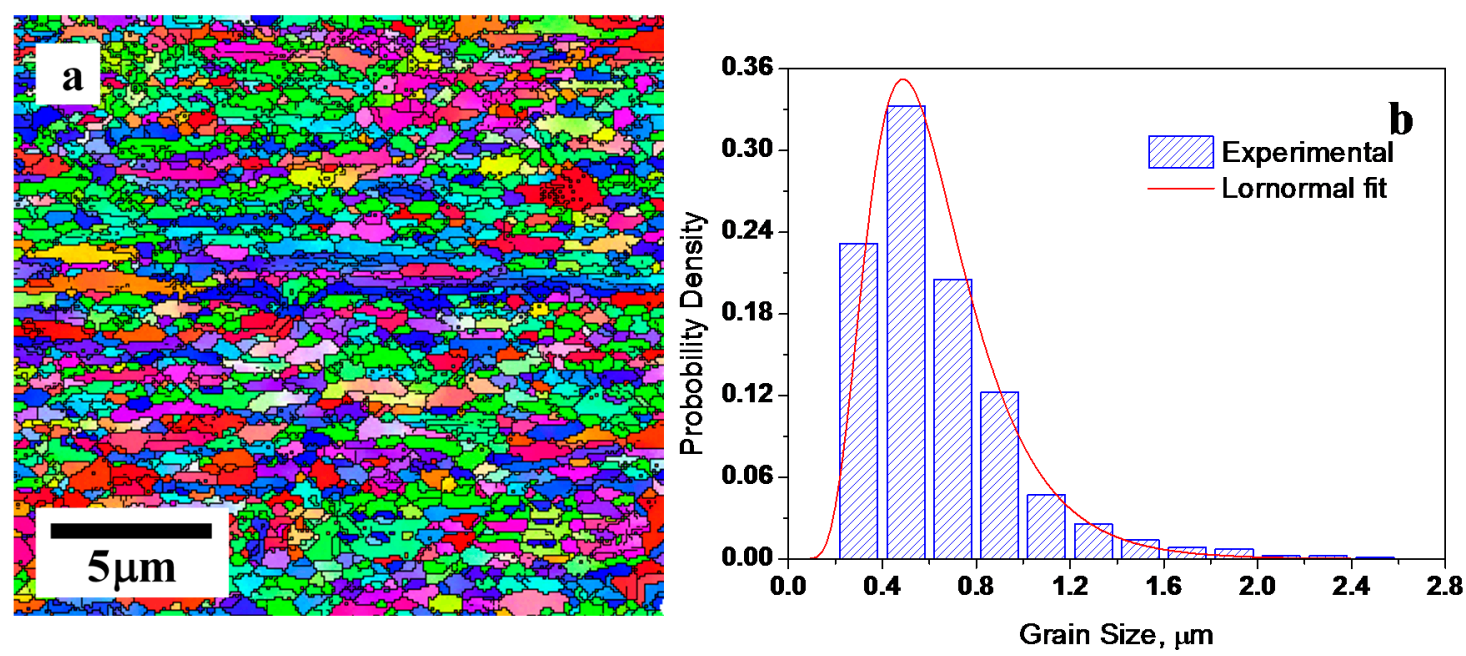

Figure 2. An electron back-scattering diffraction (EBSD) image of (a) the cross-section and (b) its grain size distribution of high purity (99.97 wt \%) copper pre-deformed by equal channel angular pressing $(\mathrm{ECAP})+$ cold rolling $(\mathrm{CR})$.

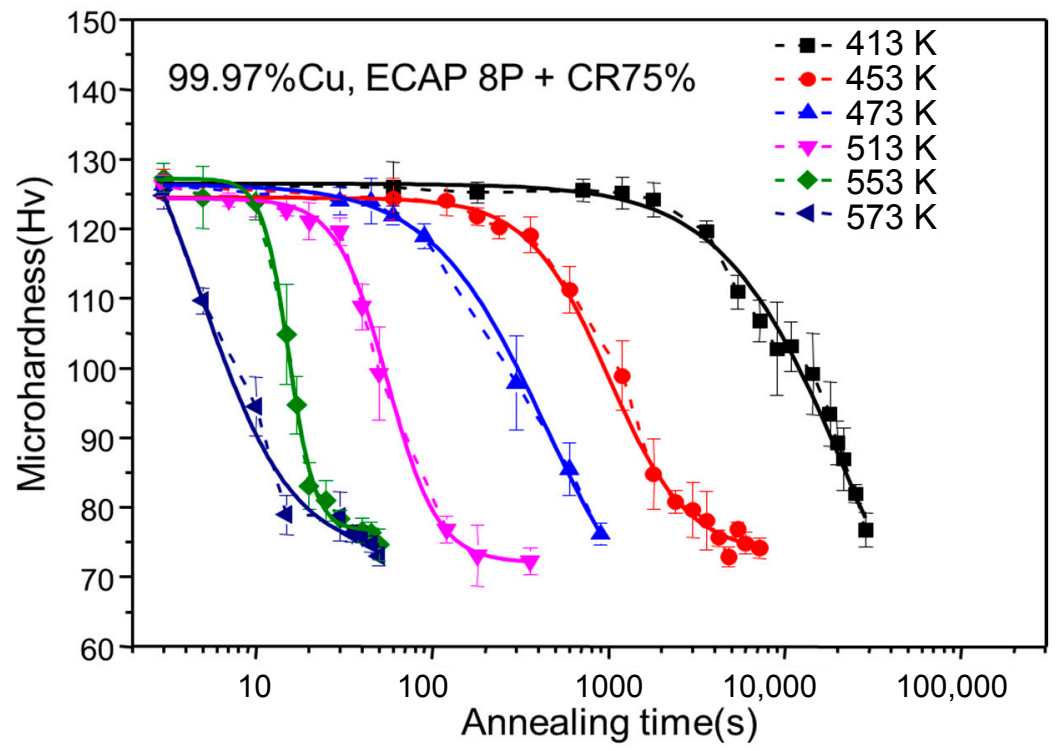

Figure 3. Variation of the microhardness vs. time at different annealing temperatures for ECAP $+\mathrm{CR}$ copper samples.

Figure $4 \mathrm{a}, \mathrm{b}$ shows the microstructure of the fully ( $\sim 95 \%$ completion) recrystallized specimens annealed at $413 \mathrm{~K}\left(140{ }^{\circ} \mathrm{C}\right)$ and $573 \mathrm{~K}\left(300^{\circ} \mathrm{C}\right)$ respectively. The recrystallized grain size after $413 \mathrm{~K} / 8 \mathrm{~h}$ annealing ranges from 1 to $15 \mu \mathrm{m}$ with an average grain size of $3.5 \pm 0.9 \mu \mathrm{m}$, while that after the $573 \mathrm{~K} / 35 \mathrm{~s}$ annealing ranges from 1 to $7.5 \mu \mathrm{m}$ with an average value of about $1.9 \pm 0.5 \mu \mathrm{m}$.

The microstructures clearly show that the microstructure becomes more homogeneous with smaller average grain size with increasing annealing temperature, which means that the recrystallized grain size has a negative dependence on the annealing temperature. Grain size data from specimens annealed at other temperatures also confirm this negative dependence, as shown in Figure 4c. It is clear from this figure that the recrystallized grain size at $~ 95 \%$ completion of recrystallization decreases, and even the distribution span of grain size at each annealing temperature also decreases upon the increase of annealing temperature. 
To compare these experimental results with the prediction of Equation (5), grain size distribution in the as-deformed matrix is needed. It has been demonstrated that the grain size $d$ distribution after severe plastic deformation follows the log normal distribution $[29,30]$.

$$
f(d ; \mu, \sigma)=\frac{1}{d \sigma \sqrt{2 \pi}} \exp \left[-\frac{(\ln d-\mu)^{2}}{2 \sigma^{2}}\right],
$$

where the two distribution parameters $\mu$ and $\sigma$ are the mean and standard deviation of $\ln d$, respectively. The number fraction of grains with a diameter $\geq d_{\mathrm{c}}\left(d_{\mathrm{c}}=2 r^{*} \cdot x_{\mathrm{c}}\right)$ is:

$$
F_{N}=1-\int_{0}^{d c} f(x ; \mu, \sigma) d x=\frac{1}{2}-\frac{1}{2} \operatorname{erf}\left(\frac{\ln d_{c}-\mu}{\sigma \sqrt{2}}\right),
$$

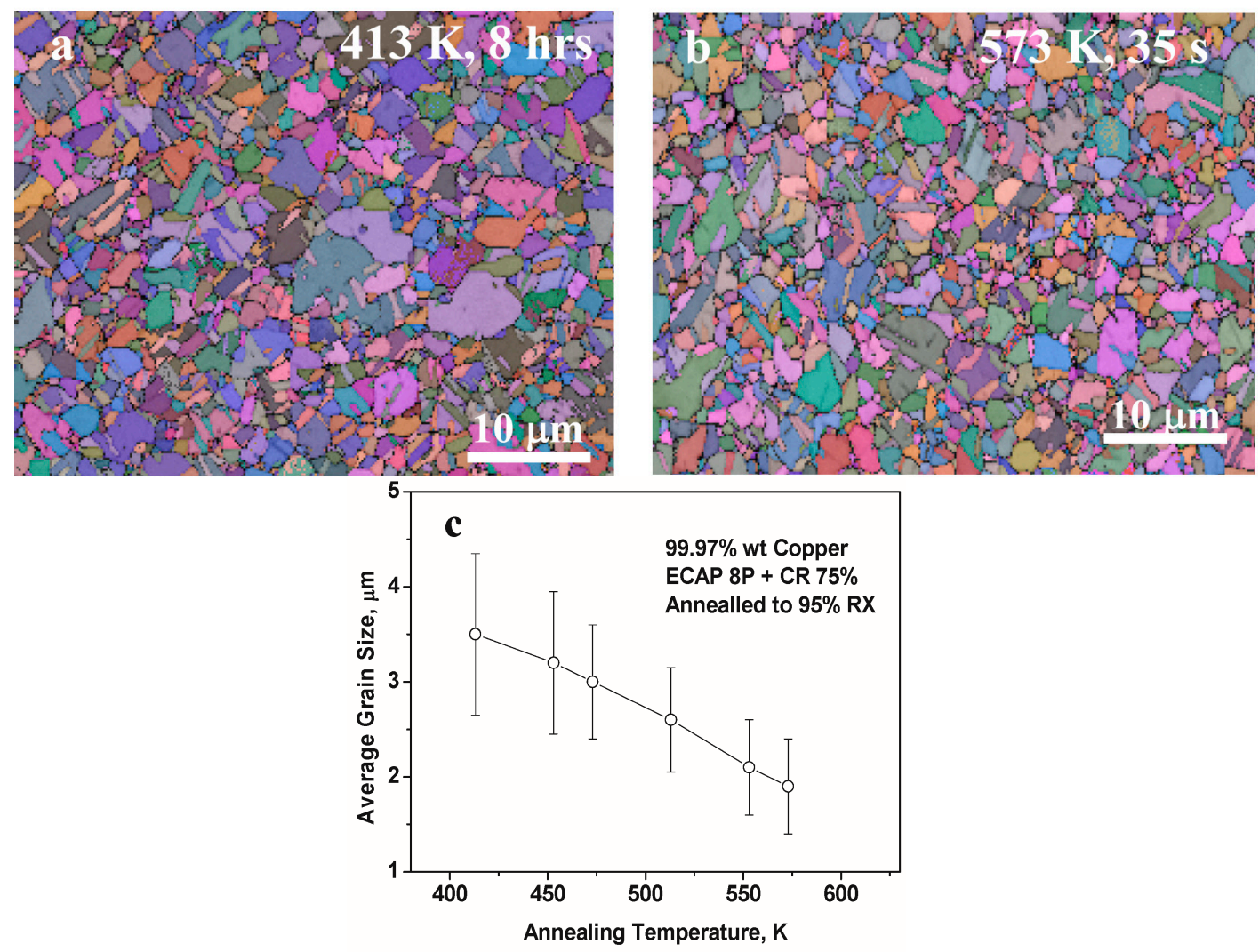

Figure 4. EBSD images after $\sim 95 \%$ recrystallization of the specimens upon annealing at (a) $413 \mathrm{~K}$ $\left(140{ }^{\circ} \mathrm{C}\right), 8 \mathrm{~h}$; (b) $573 \mathrm{~K}\left(300^{\circ} \mathrm{C}\right), 35 \mathrm{~s}$; and (c) the dependence of the recrystallized grain size $D_{\mathrm{T}}$ at $95 \%$ recrystallization $(\mathrm{RX})$ on annealing temperature.

On the other hand, from the experimental data, the number of grains in the recrystallized microstructure annealed at temperature $T$ is inversely proportional to its average grain size $D_{T}$, and the number of grains in the pre-deformed matrix is inversely proportional to its average grain size $d_{a v}$. Thus, the number fraction of grains in the pre-deformed matrix which transformed into recrystallized grains after annealing at temperature $T$ is:

$$
F_{N T}=\left(d_{a v} / D_{T}\right)^{3}
$$

Combination of Equations (7) and (8) gives:

$$
\operatorname{erf}\left(\frac{\ln d_{c}-\mu}{\sigma \sqrt{2}}\right)=1-2\left(\frac{d_{a v}}{D_{T}}\right),
$$


$d_{a v}$ can be calculated from Figure 2b, together with $\mu=-0.538$ and $\sigma=0.424$ for the lognormal distribution of grain size, and $D_{T}$ is given in Figure 4c. Thus, $F_{N T}$ and $d_{\mathrm{c}}$ for recrystallized microstructure annealed at temperature $T$ can be calculated according to Equations (8) and (9). An experimental relation of $x_{\mathrm{c}}\left(x_{\mathrm{c}}=d_{\mathrm{c}} /\left(2 r^{*}\right)\right)$ and $T$ can thus be obtained, and is shown in Figure 5 by hollow circles. The curve for $m=0.980$ from Figure $1-$ which is an analytical prediction from Equation (5) - is also plotted in Figure 5. It can be seen that the data points from experiments fit fairly well with the analytical prediction for $m=0.980$. The high value of $m(=0.980)$-which yields a good fit between analytical prediction and experimental data-reflects the high catalyzing efficiency of the pre-existing HAGB on the forming of new embryo for recrystallization.

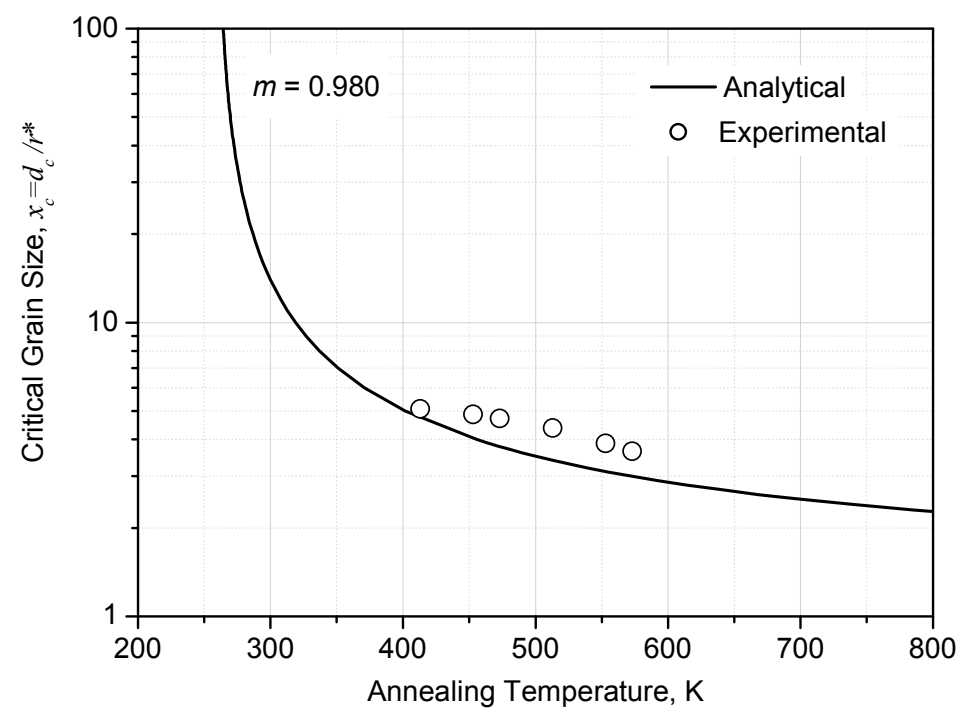

Figure 5. Comparison of analytically and experimentally obtained dependence of critical grain size for catalyzing nucleation site $\left(x_{\mathrm{c}}=d_{\mathrm{c}} / 2 r^{*}\right)$ upon annealing temperature $T$.

\section{Conclusions}

In summary, the catalyzing effect on nucleation of recrystallization from pre-existing grains with HAGB is analyzed, analogous to the size effect of foreign nucleus in heterogeneous nucleation. Analytical formulation of effective nucleation sites leads to a negative temperature dependence of recrystallized grain size, where a critical grain size $d_{c}$ pre-existing in the as-deformed matrix is formulated to be negatively dependent on the annealing temperature $T$; grains with diameter larger than this critical $d_{c}$ in the as-deformed matrix will act as effective nucleation sites for recrystallization in the subsequent annealing at $T$. The higher the $T$, the smaller the $d_{c}$, and the higher the fraction of grains in the as-deformed matrix can act as effective nucleation sites, and thus smaller recrystallized grain size is formulated. Non-isochronal annealing-where annealing time is set just enough for the completion of recrystallization at different temperatures-is conducted on a high purity ( $99.97 \mathrm{wt}$. \%) copper after room temperature severe plastic deformation. Negative temperature dependence of recrystallized grain size is confirmed, where more homogeneous and smaller grains are experimentally obtained at higher annealing temperature. The good fit between analytical prediction and experimental results unveils the intrinsic feature of the negative temperature dependence of recrystallized grain size.

Acknowledgments: This work was supported by the Chinese Ministry of Science and Technology of China under Grant No. 2012CB932203 of the National Key Basic Research Program, the Natural Science Foundation of China under Grant No. 51304123, and the Key grant Project of Chinese Ministry of Education under Grant No. 311035.

Author Contributions: Mohamed Elmasry, Yao Jiang and Ze Ning Mao performed processing of the samples; Mohamed Elmasry and Fan Liu conducted microstructure characterization; Mohamed Elmasry and Ying Liu analyzed the data; Mohamed Elmasry, Ying Liu and Jing Tao Wang developed the model and wrote the paper. 
Conflicts of Interest: The authors declare no conflict of interest.

\section{References}

1. Cathro, R.J. Tin Deposits and the Early History of Bronze. CIM Bull. 2005, 98(1088), 1-5.

2. Humphery, F.J.; Hatherly, M. Recrystallization and Related Annealing Phenomena, 2nd ed.; Elsevier: Oxford, UK, 2004.

3. Wang, Y.; Chen, M.; Zhou, F.; Ma, E. High tensile ductility in a nanostructured metal. Nature 2002, 419, 912-915. [CrossRef] [PubMed]

4. Burke, J.E.; Turnbull, D. Recrystallization and Grain Growth; Progress in Metal Physics, Pergamon Press: London, UK, 1952; Volume 3, p. 220.

5. Cahn, R.W.; Haasen, P. Physical Metallurg; North-Holland: Amsterdam, The Netherlands, 1996; Volume 3, p. 2419.

6. Rodrigues, D.L.; Silveira, J.R.F.; Landgraf, F.J.G. Combining Mager and Steinmetz: The Effect of Grain Size and Maximum Induction on Hysteresis Energy Loss. IEEE Trans. 2011, 47, 2179-2183. [CrossRef]

7. Sohn, S.S.; Lee, B.J.; Lee, S.; Kim, N.J.; Kwak, J.-H. Effect of annealing temperature on microstructural modification and tensile properties in 0.35 C-3.5 Mn-5.8 Al lightweight steel. Acta Mater. 2013, 61, 5050-5066. [CrossRef]

8. Oishi, K.; Sasaki, I.; Otani, J. Effect of silicon addition on grain refinement of copper alloy. Mater. Lett. 2003, 57, 2280-2286. [CrossRef]

9. Naether, G.; Krumnacker, M.; Pysz, G. Structure and softening of brass during accelerated recrystallization. Met. Technol. 1980, 7, 345-347. [CrossRef]

10. Mishra, S.K.; Tiwari, S.M.; Carter, J.T.; Tewari, A. Texture evolution during annealing of AZ31 Mg alloy rolled sheet and its effect on ductility. Mater. Sci. Eng. A 2014, 599, 1-8. [CrossRef]

11. Marinchenko, G.E. Mechanical characteristics and structure of molybdenum alloy $\mathrm{CM}-10$ in the temperature range of 273-1473 K. Proc. NAU 2005, 24, 59-62.

12. Eastwood, L.W.; Bousu, A.E.; Eddy, C.T. Recrystallization and grain growth in cold-worked polycrystalline metal. Trans. Metall. Soc. AIME 1935, 117, 246-264.

13. Wang, S.; Holm, E.A.; Suni, J.; Alvi, M.H.; Kalu, P.N.; Rollett, A.D. Modeling the recrystallized grain size in single phase materials. Acta Mater. 2011, 59, 3872-3882. [CrossRef]

14. Beck, P.A.; Sperry, P.R. Strain induced grain boundary migration in high purity aluminum. J. Appl. Phys. 1950, 21, 150-152. [CrossRef]

15. Molodova, X.; Gottstein, G.; Winning, M.; Hellmig, R.J. Thermal stability of ECAP processed pure copper. Mater. Sci. Eng. A 2007, A460-A461, 204-213. [CrossRef]

16. Wang, Y.L.; Lapovok, R.; Wang, J.T.; Qi, Y.S.; Estrin, Y. Thermal behavior of copper processed by ECAP with and without back pressure. Mater. Sci. Eng. A 2015, A628, 21-29. [CrossRef]

17. Fletcher, N.H. Size effect in heterogeneous nucleation. J. Chem. Phys. 1958, 29, 572-576. [CrossRef]

18. Perepezko, J.H.; Wilde, G. Melt undercooling and nucleation kinetics. Curr. Opin. Solid State Mater. Sci. 2016, 20, 3-12. [CrossRef]

19. Weinberg, M.C. The influence of finite impurity size on heterogeneous nucleation. J. Chem. Phys. 1992, 96, 9144-9146. [CrossRef]

20. Piękoś, K.; Tarasiuk, J.; Wierzbanowski, K.; Bacroix, B. Generalized vertex model of recrystallizationApplication to polycrystalline copper. Comput. Mater. Sci. 2008, 42, 584-594. [CrossRef]

21. Wang, J.T.; Zhang, Y.; Liu, J.Q. Continuous recrystallization phenomenon in high purity copper during equal channel angular pressing up to high strain at room temperature. Mater. Sci. Forum 2008, 584-586, 929-937. [CrossRef]

22. Zhang, Y.; Wang, J.T.; Cheng, C.; Liu, J.Q. Stored energy and recrystallization temperature in high purity copper after equal channel angular pressing. J. Mater. Sci. 2008, 3, 7326-7330. [CrossRef]

23. Li, Y.S.; Zhang, Y.; Tao, N.R.; Lu, K. Effect of thermal annealing on mechanical properties of a nanostructured copper prepared by means of dynamic plastic deformation. Scr. Mater. 2008, 59, 475-478. [CrossRef]

24. Takayama, A.; Yang, X.; Miura, H.; Sakai, T. Continuous static recrystallization in ultrafine-grained copper processed by multi-directional forging. Mater. Sci. Eng. A 2008, 478, 221-228. [CrossRef] 
25. Daly, R.; Zghal, S.; Njeh, N. Effects of annealing on the microstructure and properties of Cua1copper processed by Equal Channel Angular Extrusion. Phys. Procedia 2009, 2, 677-684. [CrossRef]

26. Blum, W.; Li, Y.J.; Durst, K. Stability of ultrafine-grained $\mathrm{Cu}$ to subgrain coarsening and recrystallization in annealing and deformation at elevated temperatures. Acta Mater. 2009, 57, 5207-5217. [CrossRef]

27. Flinn, J.E.; Field, D.P.; Korth, G.E.; Lillo, T.M.; Macheret, J. The flow stress behavior of OFHC polycrystalline copper. Acta Mater. 2001, 49, 2065-2074. [CrossRef]

28. Iwahashi, Y.; Horita, Z.; Nemoto, M.; Langdon, T. The process of grain refinement in equal-channel angular pressing. Acta Mater. 1998, 46, 3317-3331. [CrossRef]

29. Islamgaliev, R.K.; Chmelik, F.; Kuzel, R. Thermal stability of submicron grained copper and nickel. Mater. Sci. Eng. A 1997, 237, 43-51. [CrossRef]

30. Gendelman, O.V.; Shapiro, M.; Estrin, Y.; Hellmig, R.J.; Lekhtmakher, S. Grain size distribution and heat conductivity of copper processed by equal channel angular pressing. Mater. Sci. Eng. A 2006, 434, 88-94. [CrossRef] article distributed under the terms and conditions of the Creative Commons Attribution (CC BY) license (http:/ / creativecommons.org/licenses/by/4.0/). 